
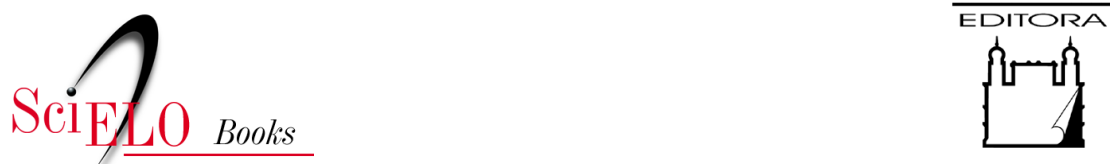

FIOCRUZ

\title{
3. Etnografia da triagem
}

\author{
Armelle Giglio-Jacquemot
}

\section{SciELO Books / SciELO Livros / SciELO Libros}

GIGLIO-JACQUEMOT, A. Etnografia da triagem. In: Urgências e emergências em saúde: perspectivas de profissionais e usuários [online]. Rio de Janeiro: Editora FIOCRUZ, 2005, pp. 45-55. Antropologia e Saúde collection. ISBN: 978-85-7541-378-4. https://doi.org/10.7476/9788575413784.0005.

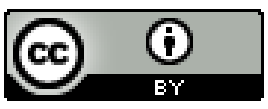

All the contents of this work, except where otherwise noted, is licensed under a Creative Commons Attribution 4.0 International license.

Todo o conteúdo deste trabalho, exceto quando houver ressalva, é publicado sob a licença Creative Commons Atribição 4.0.

Todo el contenido de esta obra, excepto donde se indique lo contrario, está bajo licencia de la licencia Creative Commons Reconocimento 4.0. 


\title{
3 \\ Etnografia da Triagem
}

\section{Ambigüiddde dos Prontos-socorros}

Como apontam, com justeza, Dodier e Camus (1997a: 109), os prontos-socorros dos hospitais públicos são caracterizados por uma forte ambigüidade:

\begin{abstract}
de um lado, são totalmente abertos aos pedidos exteriores, visto que, em princípio, devem poder acolher o público de maneira permanente e que todos os pedidos de atendimento hão de ser examinados; de um outro lado, e especialmente nos hospitais universitários, os prontos-socorros são lugares seletivos, dado que são concebidos em prioridade para um leque circunscrito de patologias essas suscetíveis de levar à morte ou a lesões irreversíveis se não forem atendidas muito rápido.'
\end{abstract}

A ambivalência dos prontos-socorros também é assinalada por Joseph (1998: 163), quando, em um artigo sobre as urgências psiquiátricas, ele assinala que "as urgências ora designam sintomas que engajam um prognóstico vital, ora traduzem a acessibilidade de um sistema de atendimento à saúde a todos os usuários que se apresentam". 2

Essa ambigüidade notada pelos autores, por ocasião de pesquisas realizadas na França, verifica-se nos prontos-socorros dos hospitais públicos brasileiros. Aliás, não está presente somente nesses lugares, mas no conjunto dos diversos serviços oferecidos pela rede pública de atendimento às urgências/emergências, tais como as centrais de chamadas e os serviços móveis de ajuda de urgência (viaturas de bombeiros, ambulâncias). A urgência remete a duas noções dualistas: uma que diz respeito a um princípio de acessibilidade garantido a todos, isto é, qualquer indivíduo que pede um atendimento de urgência deve poder ser atendido a qualquer hora do dia e da noite, curtocircuitando as etapas preliminares que atrasariam o seu atendimento; a outra diz respeito a um princípio de especialidade e seleção, pois os diversos profissionais que atuam no domínio da urgência estão preparados, ou se formando, para atender um conjunto delimitado de patologias, ou situações de saúde, consideradas 'urgências verdadeiras'.

A coexistência desses dois princípios de abertura e de seleção está na raiz de uma tensão cujas traduções concretas podem ser observadas nos comportamentos e nas reações daqueles que, atuando na rede do atendimento às urgências/emergências, 
enfrentam um fluxo de pedidos que chegam sob formas heterogêneas e que dizem respeito a problemas de natureza muito diversa, e daqueles que, na busca de um alívio para seus sofrimentos, solicitam um atendimento de urgência.

As manifestações dessa tensão se deixam observar, especialmente, nas interaçōes entre essas duas categorias de pessoas e na maneira como os pacientes são encarados, triados e tratados até o atendimento no pronto-socorro.

\section{Percursos dos Usuírios e Agentes da Triagem}

Ao contrário dos usuários que o sociólogo Jean Peneff (2000:10) encontrou nos prontos-socorros dos hospitais públicos que estudou na França, ${ }^{3}$ "pouco homogêneos em suas características sociais" e constituindo "populações heterogêneas", os usuários do pronto-socorro do Hospital das Clínicas de Marília são, em sua maioria, "pacientes SUS", ${ }^{4}$ pertencendo às camadas sociais inferiores, com baixo nível de renda e de educação.

Os percursos que eles seguem até conseguir um atendimento, assim como os agentes da triagem que encontram em seu caminho, são diversos. Existem várias maneiras de eles chegarem ao pronto-socorro - a pé, de ônibus, de automóvel, ${ }^{5}$ de ambulância da prefeitura, de viatura de bombeiros ${ }^{6}$ - e delas depende, em grande parte, a configuração de seus percursos e as modalidades de seu atendimento.

\section{Checar a Ṕ́, de Carro, de Ônibus:}

\section{$\Lambda$ TRIACEM DOS SECURANCSAS, PORTEIROS E RECEPCIONISTAS}

As pessoas que vão (ou são levadas) até o pronto-socorro a pé, de ônibus ou de automóvel, têm em comum o fato de se apresentarem sem ter passado por nenhuma seleção preliminar: ${ }^{7}$ o motivo da sua vinda e a 'urgência' de seu caso só começam a ser apreciados no momento em que chegam na entrada do pronto-socorro onde encontram um primeiro profissional, o segurança, que, ficando em pé do lado da porta, olha para elas e pergunta-lhes a razão da sua vinda.

"Eu apenas oriento as pessoas que chegam na porta. A nossa função aqui é fazer a triagem", explica um dos seguranças que atuam na entrada do pronto-socorro. De fato, este profissional não-médico está oficialmente encarregado de liberar a entrada no próprio pronto-socorro para quem está no lugar certo, indicar outras entradas do hospital para quem chegou no lugar errado. Compete também a ele vigiar o número de pessoas que penetram no pronto-socorro, pois suas instruções são de não deixar entrar mais do que um acompanhante por paciente. Na prática, ele aplica essa regra de maneira mais ou menos estrita, segundo os pacientes e a afluência. A ele também cabe vigiar as saídas para impedir as de certos pacientes que, levados pela polícia, pelos bombeiros ou motoristas de ambulância, tentam deixar o pronto-socorro antes serem atendidos.

Portanto, do lado de seus encargos oficiais, os seguranças da porta de entrada ainda têm os não declarados que ampliam o conjunto de suas missões. Assim, cabe a eles, implicitamente, manter a ordem dentro e fora da sala de espera. Sua intervenção diante de pacientes manifestando agitação, agressividade ou comportamentos provo- 
cadores é que revelou, no decorrer da pesquisa, claramente sua função repressiva não declarada. Em algumas ocasiões, chegaram a ter atitudes agressivas e até violentas com pacientes. Tratava-se sempre de homens alcoolizados e, aliás, notava-se que a reação das outras pessoas que esperavam atendimento era geralmente de indiferença. De qualquer jeito, mesmo que raramente explicitada em ações, a presença e o papel repressivos desses agentes estão tão bem sugeridos pelo uniforme, que não escapam a ninguém.

O segurança não está formalmente autorizado a se opor à entrada de quem deseja ser atendido, conforme a aplicação do princípio de acessibilidade a todos do pronto-socorro público. Em termos de seleção, seu papel está declaradamente limitado a uma simples triagem do público em relação à sua orientação certa no hospital. Entretanto, no nível das práticas, a observação revela que esse agente sem formação médica desempenha um papel muito significativo na triagem das urgências.

Em primeiro lugar, acontece do segurança impedir a entrada no pronto-socorro de pessoas que procuram um atendimento. Nas situaçôes presenciadas, que foram poucas, tratava-se de indivíduos embriagados ou ainda vistos como 'loucos', segundo as próprias palavras dos seguranças envolvidos. Eles apresentavam comportamentos esquisitos e falas incoerentes ao mesmo tempo em que um estado físico julgado 'bom' por esses profissionais, isto é, bom o suficiente para eles acharem que não necessitavam de uma consulta no pronto-socorro e, por conseqüência, ihes barrarem a entrada: aos "bêbados", porque iriam arrumar confusão na sala de espera, e porque "bêbado" como "drogado" "não é doente, é uma escolha", segundo seus próprios comentários; aos "loucos", porque também iriam arrumar confusão e "não são doentes", isto é, não padecem de nenhum mal físico. Voltaremos a esse ponto em um capítulo posterior, mas sua simples evocação no momento já demonstra o quanto as representações da urgência, os preconceitos e julgamentos morais dos seguranças podem se traduzir, concretamente, por comportamentos que os levam a desempenhar um papel importante na triagem das pessoas que se apresentam na porta do pronto-socorro.

Em segundo lugar, o caminho que o segurança aponta para as pessoas que querem ser atendidas no pronto-socorro depende da breve avaliação que ele faz de seu estado de saúde. Esta é baseada em dados orais fornecidos pelos pacientes (e/ou os acompanhantes) e em sinais visuais que ele lê no seu corpo e comportamento. A fala da pessoa que quer entrar é suscitada pelo próprio "pois é?" do segurança que, sob essa forma indireta, a interroga sobre seus motivos. Geralmente a resposta que consegue é breve e mínima. Limita-se a frases curtas do tipo: "passei mal", "é para consulta", "tenho dor", "me sinto adoentado". Entretanto, o segurança não insiste e libera a entrada. $\mathrm{Na}$ porta do pronto-socorro, quem chega está geralmente pouco disposto a falar com o segurança: quer entrar. Aliás, contar-lhe suas razões e problemas é exporse a outros desconhecidos, pois a entrada do pronto-socorro é um lugar onde se encontram muitas pessoas, pacientes e acompanhantes em situação de espera.

Em função de sua apreciação do estado de saúde do paciente, a partir das informações que consegue oralmente e, sobretudo, visualmente, o segurança o encaminha para a recepção, onde tem de preencher sua ficha de entrada, ou direto para a área de atendimento médico. ${ }^{8} \mathrm{O}$ primeiro encaminhamento representa a situação mais co- 
mum: é esse que o segurança indica para as pessoas que, segundo ele, podem esperar. Mas se o problema do paciente lhe parece urgente, ele o leva a curto-circuitar o conjunto das etapas do processo comum, apontando-lhe, com um gesto da mão, a direção da área de atendimento médico onde se encontra um outro segurança, ou um porteiro, que guarda a porta de separação, geralmente fechada, entre essa área e a sala de espera.

Compartilhando ou não a apreciação do primeiro segurança, o segundo tenta ou impede a entrada do paciente na área de atendimento médico. Quando julga não ser urgente o problema do paciente a ele encaminhado, manda-o preencher sua ficha e mostra-lhe a recepção. Muitas vezes observei situações em que os pacientes são objeto de ordens contraditórias dos seguranças e porteiros - mandados para lá, mandados para cá. No próximo capítulo há a descrição e a análise de uma delas. Trata-se de situações que seriam cômicas, se não fossem tão penosas para quem está angustiado e sofrendo. Em compensação, se o segundo segurança também fica convencido da urgência do caso, pede para o paciente esperar e entra na área de atendimento à procura de um médico (ou residente de medicina) no intuito de chamar sua atenção e de incitálo a sair da área de atendimento para vir "dar uma olhada" naquele paciente.

Mesmo não tomando a responsabilidade da entrada direta do paciente na área médica, pois larga a decisão na mão de um especialista médico, o segundo segurança (ou o porteiro) não deixa de ter, então, uma influência notável na triagem porque assinala a existência de um paciente a médicos e enfermeiras ${ }^{9}$ que, por ficarem dentro de um lugar fechado e irem pouco à sala de espera, sabem muito pouco do que existe e acontece nela. Estes tomam conhecimento dos pacientes a serem atendidos após a leitura das fichas que as recepcionistas depositam, periodicamente, ou em uma caixa de madeira na sala de espera, fixada na parede ao lado da entrada da pequena sala de 'triagem clínico geral' (fichas dos pacientes chamados nessa sala), ou em uma caixa que fica dentro da área de atendimento médico (fichas dos pacientes atendidos por especialidades).

Quando, uma vez fora da área de atendimento, e depois de dar uma olhada e conversar brevemente com o paciente (e/ou seus acompanhantes), o médico também fica convencido da possível urgência de seu caso, ele o leva para dentro da área onde será atendido mais ou menos rápido, em função, entre outras coisas, da avaliação mais fina do grau de urgência de seu caso, do número de pessoas que já estão sendo atendidas e da ordem de prioridade na qual vai estar inserido na lista dos que já estão esperando. Em compensação, quando, ao contrário do segurança, o médico avalia o estado/problema como não urgente, ao paciente é solicitado que preencha uma ficha e espere sua vez. Dependendo do que for indicado pela recepcionista na ficha desse paciente, a partir das respostas que ela obtém sobre o motivo de sua vinda, ele será chamado na pequena sala de 'triagem clínico geral' ${ }^{10}$ ou na área de atendimento.

Aliás, as recepcionistas também desempenham um papel significativo na triagem dos pacientes. Quando estimam que um paciente se encontra em um estado possivelmente grave - por falarem com ele e o verem no momento em que se apresentam para fornecerem os seus dados - elas também avisam ao médico no momento em que vão depositar as fichas nas caixas. A intervenção das recepcionistas, como a dos seguranças e a dos porteiros, pode traduzir-se em um tempo menor de espera pelo paciente que conseguiu chamar a sua atenção. 


\section{Valor Mobilizador dos Pacientes}

Como se pôde observar, existem dois percursos para os pacientes que, vindo a pé, de ônibus, de carro, conseguem sua entrada no pronto-socorro: ou seguem o caminho da maioria e preenchem sua ficha para depois esperar pelo atendimento na sala de espera, ou curto-circuitam todas as etapas, obtendo a entrada direta na área médica onde recebem um atendimento que pode, ou não, ser imediato.

Para conseguir percorrer o segundo caminho, o paciente tem de estar em um estado apreciado como urgente por profissionais que não têm nenhuma formação médica (os seguranças, porteiros, recepcionistas) e que nem sempre concordam na avaliação; é só no final que ele é visto por um médico que decide sobre o grau de urgência de seu caso. Isso significa que para tomar o caminho mais rápido o paciente tem de convencer várias categorias de profissionais (não médicos e médicos) que, em face das diferentes determinações socioculturais das camadas de população às quais pertencem e das diferentes profissões e competências que exercem, certamente não compartilham o mesmo conhecimento nem o mesmo universo de representação do que remete à saúde, em geral, e à urgência e à emergência em saúde, em particular.

O que possuem os pacientes que perfazem o segundo caminho em relação aos que são encaminhados para o primeiro? Eles têm o que Dodier e Camus (1997a: 113) chamam de um "valor mobilizador alto". O pessoal que atua no atendimento às urgências e emergências (seguranças, porteiros, recepcionistas, enfermeiras, médicos, mas também motoristas de ambulâncias, bombeiros) reage por uma mobilização diferenciada segundo os pacientes. Cada paciente adquire um valor mobilizador mais ou menos grande que se traduz de maneira concreta na triagem pelo lugar que lhe é atribuído na hierarquia e na ordem das prioridades. Maior a força mobilizadora de seu caso, menor o tempo de espera até o atendimento. Assim, os pacientes que têm o valor mobilizador mais baixo - os que Dodier e Camus (1997a: 115) chamam de pacientes "tolerados" são os que mais aguardam a sua vez. Aliás, não é raro o pessoal do pronto-socorro acabar se livrando deles justamente pela duração da espera: desistindo de serem atendidos, acabam indo embora, geralmente muito descontentes e magoados.

Os critérios nos quais os vários profissionais do pronto-socorro se apóiam para hierarquizar o valor mobilizador dos pacientes são de ordens distintas. Será feito seu exame nos capítulos voltados à questão de suas representações da urgência e da emergência.

\section{Citegar com 0192 ou 0 193:}

\section{A TRIAGEM DOS MOTORISTAS DE AMBULÂNCIA E BOMBEIROS}

À diferença dos pacientes que vão ao pronto-socorro a pé, de carro ou de ônibus, os que chegam de ambulância ou de viatura de bombeiros já passaram por várias avaliações de seu estado de saúde quando chegam à porta do pronto-socorro.

Trazidos pelos bombeiros ou motoristas de ambulância, eles têm garantida sua entrada no pronto-socorro. O segurança não os interroga sobre os motivos de sua vinda nem aos profissionais que os acompanham: deixa-os passar. É que, quando chegam, 
esses pacientes já estão no final de um primeiro percurso ligado a um primeiro processo de seleção que teve início fora do pronto-socorro. Na fase que antecede sua chegada, eles já convenceram os diversos profissionais que os auxiliaram até o pronto-socorro. Persuadiram-nos não necessariamente da urgência (ou emergência) de seu caso, mas conseguiram, pelo menos, convencer de sua possível seriedade o atendente das centrais de chamada (192 ou 193). Antes de chegar ao pronto-socorro, eles já passaram, então, por uma triagem realizada, primeiro, pelo atendente que tomou a decisão de mandar um veículo de socorro e, depois, pelos profissionais, motoristas de ambulância ou bombeiros que foram buscá-los.

Uma vez enviadas, as equipes de ajuda móvel são obrigadas, por questões de responsabilidade, a atender a pessoa objeto da chamada e a levá-la para o prontosocorro, qualquer que seja a avaliação feita uma vez no lugar; isto é, mesmo se são levadas a apreciar o estado (situação) de saúde do paciente como menos sério (e até não sério) do que o descrito no telefone, como acontece muitas vezes. " Contudo, nem por isso, sua avaliação deixa de ter incidência sobre a triagem, pois em função dela, tanto os bombeiros do 193 quanto os motoristas do 192 agem com 'mais' ou 'menos' rapidez até a entrega do paciente no pronto-socorro; também passam a informação da urgência ou não do caso que estão levando para o segurança da porta de entrada do pronto-socorro, induzindo, assim, a maneira como o paciente que transportam vai ser considerado e tratado na chegada, como será visto a seguir.

Para os pacientes que vão ao pronto-socorro de veículos móveis de ajuda médica urgente, a triagem começa, então, bem antes de eles serem examinados por um médico. Ela se inicia na dependência das apreciações dos profissionais das centrais - atendentes, motoristas, bombeiros - e continua no pronto-socorro, onde, em função das apreciações de outros profissionais não médicos, os pacientes são levados a percorrer um dos dois caminhos descritos anteriormente.

Por iniciativa dos próprios motoristas das viaturas e ambulâncias, o segurança da entrada recebe informações sobre a gravidade do caso, antes de o paciente passar pela porta. Existem códigos gestuais entre ele e os motoristas. Quando estão ainda subindo a rampa de acesso ao pronto-socorro, estes usam de sinais para indicar o grau de urgência com que seu paciente tem de ser atendido, uma vez o veículo parado na porta do pronto-socorro. Se o motorista, através do pára-brisa, faz o gesto de erguer um dedo, é que o caso do paciente que está levando é, segundo os seguranças, "urgente". Vendo esse sinal, o segurança da entrada se dirige a uma campainha que se encontra perto dele na sala de espera, ${ }^{12} \mathrm{e}$ a toca apenas uma vez, avisando a equipe médica da chegada de uma 'urgência'. Se o motorista mostra dois dedos, ou se dá o sinal de luz ou ainda um toque de sirena, é que se trata de uma 'emergência', que exige uma intervenção rápida da equipe médica. Neste caso, o segurança avisa tocando a campainha duas vezes. Enfim, se o motorista não faz nenhum gesto, é que seu paciente não precisa de atendimento urgente na chegada, segundo a avaliação dos que o transportam.

É nessa terceira categoria que se encaixa a maioria dos pacientes que chega de ambulância da prefeitura e de viatura do Resgate: seu estado de saúde não é julgado "urgente" pelas equipes de socorro . Entretanto, são geralmente atendidos mais rápido do que os que chegam a pé, de ônibus, de carro particular. Essa constatação se verifica 
ainda mais freqüentemente no caso dos pacientes trazidos de viatura pelos bombeiros que, muitas vezes, conseguem uma entrada imediata na área de atendimento médico, acompanhados por bombeiros que foram buscá-los. Ainda mais rápido é $o$ atendimento se, ao sair da viatura, eles não entram andando, mas deitados em uma maca. A mesma observação pode ser feita em relação aos pacientes trazidos por ambulâncias do 192 (da prefeitura), apesar de estes serem, geralmente, levados menos a sério pelo pessoal que atua no pronto-socorro do que aqueles que chegam com bombeiros.

Essa última constatação aponta para a menor credibilidade das ambulâncias da prefeitura em comparação com as viaturas do corpo de bombeiros, no que diz respeito à urgência e à gravidade dos casos que transportam para o pronto-socorro. $\mathrm{O}$ valor mobilizador que adquire um paciente pelo simples fato de chegar com os bombeiros se deixa ler tanto nas atitudes e comentários das pessoas que esperam na sala de espera, quanto nos comportamentos do pessoal que trabalha no pronto-socorro. As primeiras fixam a viatura quando chega, e $o$ ambiente torna-se mais tenso na espera do paciente que vai sair. Uma vez fora da viatura, elas o acompanham com o olhar, à procura de sinais confirmando a gravidade de seu estado. Seus comentários - "o que chega de bombeiros é grave", "é urgência mesmo" - também evidenciam que, na concepção do público, quem chega de viatura do Resgate está potencialmente em um estado muito sério. $\mathrm{E}$ isso mesmo se, muitas vezes, os pacientes trazidos pelo Resgate não são considerados "urgentes" pelos próprios bombeiros, assim como eles comentam e, aliás, lamentam. Quanto ao pessoal que atua no pronto-socorro, particularmente o da enfermagem, mostram-se mais disponíveis e rápidos quando se trata de ir buscar um paciente que chega com os bombeiros, do que um que chega de ambulância ${ }^{13}$ ou, ainda pior, que chega de carro particular. Neste último caso, o segurança geralmente nem toca a campainha, qualquer que seja o estado do paciente $\mathrm{e}$ a necessidade de ajuda.

A maior credibilidade do Resgate em comparação com as ambulâncias do 192 explica-se por vários motivos. É que aquele geralmente presta socorro nos acidentes de trânsito e, por consequiência, leva para o pronto-socorro as vítimas mais espetaculares em termos de ferimentos aparentes. No espaço público, os bombeiros têm também uma visibilidade bem superior a dos motoristas de ambulâncias, quer seja pelo barulho de suas sirenas, pela cor vermelha e a aparência imponente dos seus veículos, quer seja por seu uniforme e sua freqüente atuação nas vias públicas. Enfim, eles contam geralmente com uma fama muito boa entre a população, que elogia a eficácia e a rapidez do socorro por eles prestado. Mesmo desfrutando de uma credibilidade invejável, os bombeiros do Resgate lastimam sua diminuição progressiva no meio médico e incriminam a demanda. Assim, segundo eles, os médicos dão menos atenção hoje aos pacientes que levam para o pronto-socorro porque o Resgate é cada vez mais chamado para atender casos que não são "emergências", o que se traduz por uma desvalorização de sua atuação. "Antes era uma beleza, hoje os médicos não dão bola, nem saem mais", diz um bombeiro que assim expressa a perda de credibilidade sentida por muitos. E, de fato, médicos do pronto-socorro se queixam dos bombeiros: "eles atendem qualquer pedido, não tem triagem" é um comentário comum.

O que dizer então do 192, cujos motoristas e ambulâncias sofrem de uma desconsideração que se estende até aos pacientes que transportam? Atendendo muitos 
casos não considerados como emergências nem urgências pelos profissionais, médicos e não-médicos, as ambulâncias levam ao pronto-socorro muitos pacientes que, dentro das próprias categorias utilizadas pelos motoristas, bombeiros, enfermeiros e médicos, são ditos "casos sociais" e "casos psiquiátricos". Também levam muitos "casos clínicos" que não apresentam sinais de gravidade aparente, em outros termos, casos não espetaculares. Além disso, servem para o transporte inter-hospitalar e, sobretudo à noite, para o transporte de pacientes que, uma vez atendidos no pronto-socorro, não têm como voltar para casa. Enfim, elas sofrem de uma desconsideração que diz respeito não imediatamente ao 192, mas à saúde pública, a qual são, com justeza, assimiladas.

A imagem negativa que os usuários têm do atendimento público também envolve as ambulâncias. Aliás, essa observação pode ser generalizada à população em geral. A representação positiva do Resgate em contraposição à negativa das ambulâncias se traduz, por exemplo, por comportamentos muito diferenciados na rua. Tendo acompanhado motoristas de ambulância e bombeiros nas suas saídas, notei os comportamentos diferentes dos motoristas - de carros particulares, ônibus e caminhão - quando o veículo de socorro que pedia a passagem era o do Resgate ou do 192: no primeiro caso, esforçavam-se geralmente para liberar a via; no segundo, não faziam nada, simplesmente ignoravam a ambulância. Claro que a potência das sirenas do Resgate, a autoridade militar que representam os bombeiros, assim como o poder que detêm, agem no sentido de coagir os motoristas, e essa pressão os motoristas de ambulâncias não têm condição de exercer. Mas não é só isso: os primeiros são levados bem mais a sério do que os segundos, seu trabalho e os pacientes que transportam também.

\section{LIGAR PARA 0192 OU 0193 :}

\section{A TRLAEM DOS ATENDENTES}

Voltando à questão da triagem dos pacientes que chegam ao pronto-socorro com os bombeiros do 193 ou com os motoristas do 192, importa sublinhar o quanto é crucial a avaliação feita de seu estado (ou situação) de saúde pelos atendentes das centrais, pois a decisão de "soltar um veículo" e o momento escolhido para fazê-lo dependem deles. Sua apreciação é que desencadeia todo o processo de ajuda e de triagem. Aliás, muitos solicitantes estão cientes disso, pois recorrem a vários estratagemas para conseguir a vinda - e não só a vinda, mas a vinda rápida - de um veículo, assunto que será abordado mais adiante.

Um momento decisivo da triagem se dá, então, no telefone. Os atendentes não são profissionais da saúde e nem todos receberam uma formação de pronto-socorrismo. A partir das perguntas que fazem aos solicitantes, tentam orientar a conversa de maneira a obter informações sobre vários pontos, entre os quais, a identidade do solicitante e da pessoa para quem liga, o problema de saúde que motiva a chamada e o lugar aonde mandar a ambulância. ${ }^{14} \mathrm{~A}$ maioria dos solicitantes muitas vezes nem pertencem à família do paciente. Não é raro eles falarem que desconhecem a pessoa objeto de sua solicitação, mas geralmente dizem ser vizinhos ou conhecidos, ${ }^{15}$ o que dificulta bastante o trabalho do atendente, pois muitos deles ignoram tanto o nome da pessoa a socorrer quanto o que está acontecendo com ela. 
Quando, no final de sua conversa com o solicitante, o atendente recolheu informações que o levam a pensar, primeiro, que a chamada é séria, e, segundo, que o estado de saúde descrito é grave ou pode vir a se tornar como tal se nada for feito, ele libera uma ambulância. Esta não sai necessariamente de imediato. Depende de ter uma disponível no momento da chamada e também se há solicitações anteriores ainda não atendidas, $o$ atendimento deste pedido vai ser inserido na ordem das prioridades, segundo a apreciação de seu grau de urgência.

Os atendentes não liberam um veículo só para os casos que julgam urgentes ou emergentes. Mais adiante será visto que, muitas vezes, "na dúvida", como eles mesmos dizem, preferem mandar do que ser responsabilizados mais tarde, e com eles a Central, por não ter mandado. Essa constatação se verifica sobretudo na Central de Ambulâncias, pois a do 193 é mais seletiva. Esta faz a triagem dos tipos de urgências a serem atendidos pelo Resgate - a saber, principalmente, os que decorrem de acidentes (de carro, atropelamentos, quedas) - e encaminha os pedidos que fogem de suas atribuições ${ }^{16}$ para a Central de Ambulâncias, pedindo para os solicitantes ligarem para o 192, pois "seu caso não é dos bombeiros". Em comparação, a Central de Ambulâncias parece com o gargalo de um funil para o qual acabam convergindo muitos pedidos de ajuda que não foram atendidos por outras instâncias, tais como o Resgate, o Bem-Estar Social ${ }^{17}$ e a Polícia Militar. Ela está sobrecarregada com uma demanda que a afasta, de maneira considerável, de sua função declarada.

Assim, a triagem do 192 se efetiva menos na seleção dos casos a serem atendidos - porque, afinal, a maioria das chamadas recebe uma resposta favorável ${ }^{18}$ - do que no tempo da demora até o atendimento ser prestado. Nesse ponto, a Central parece muito com o pronto-socorro. É comum os atendentes responderem positivamente a uma chamada para um problema que não acham urgente, acrescentando "vai demorar porque não tem ambulâncias no momento"; mesmo, aliás, se sobrar uma, pois reservam a ambulância ainda disponível para uma eventual urgência/emergência.

No 193, a situação é inversa: a triagem se realiza mais na seleção dos casos que são atendidos (e, por essa razão, as saídas das viaturas do Resgate são bem menos numerosas) do que no tempo que levam as viaturas para chegar no lugar, pois, de maneira geral, é breve, uma vez que o pedido do solicitante recebe uma resposta favorável por parte do atendente.

\section{Ем Sимк...}

Todas as categorias de profissionais anteriormente citados, mesmo que, em sua maioria, não médicos, participam da triagem das ditas 'urgências/emergências médicas', cada um em seu papel, cada um em seu lugar. A interdependência e a interligação de suas apreciações e avaliações desenha uma corrente dinâmica de decisões e ações que, afinal, determina a qualidade dos cuidados e do socorro prestados em termos de rapidez e eficácia.

Para os usuários, essa corrente é um percurso, mais ou menos longo, demorado e diversificado. Até chegarem ao destino final e receberem a ajuda e os cuidados médi- 
cos esperados ou impostos, passam por várias etapas. Alguns, aliás, não atingem o destino final, seja porque desistem no caminho - ficando em casa ou voltando para ela -, seja porque se recusam a embarcar ou ainda morrem antes de chegar. Para quem a faz, essa viagem tem implicações e traduções muito práticas e concretas.

As observações de campo revelam que, dito de maneira um tanto caricatural e provocadora, a melhor maneira de conseguir um atendimento rápido no pronto-socorro é chegar de viatura de bombeiros, deitado em uma maca (mesmo que consciente), apresentando alguma marca impressionante visível no corpo, como sangue, feridas e fraturas expostas... O conjunto desses sinais heterogêneos garante a entrada imediata na área de atendimento médico, qualquer que seja o estado de saúde do paciente, só avaliado depois por médicos. O contrário acontece com quem chega por meios próprios, passa em pé pela porta do pronto-socorro, e se queixa de algum problema que não apresenta nenhum sinal manifesto no corpo ou no comportamento: este paciente tende a esperar sua vez, até por muito tempo, sobretudo se fica quieto, sentado na cadeira. A não ser se ele de repente desmaiar: neste caso, seu atendimento torna-se imediato.

As avaliações dos vários agentes da urgência/emergência - cujas decisões e ações impulsionam sua dinâmica e sua configuração aos percursos dos usuários - são informadas a partir de um conhecimento diverso constituído, com o tempo, através da aquisição teórica ou/e empírica de certos elementos de conhecimento médico, e outros decorrentes de sua vivência e de experiência de sua função. Suas apreciações se embasam em representações da urgência/emergência que são importantes apreender para entender suas práticas, e é precisamente a partir da observação minuciosa e perseverante dessas práticas que as representações dos atores da urgência/emergência podem ser atingidas, em um balanço comparativo com os discursos por eles proferidos.

O que é uma urgência, uma emergência, o que é considerado grave, o que suscita a mobilização por parte dos médicos, dos seguranças, porteiros e recepcionistas, dos motoristas de ambulância e atendentes das centrais? E por parte dos usuários? É a essas perguntas que os próximos capítulos ambicionam responder.

\section{Notas}

: Tradução livre.

2 Tradução livre.

3 Trata-se dos prontos-socorros de três hospitais da Assistência Pública de Paris (AP): Beaujon (Clichy), La pitié-Salpétrière (Paris) e Ambroise-Paré (BoulogneBillancourt).

4 Empresto aqui uma expressão corrente entre os profissionais do pronto-socorro.

5 Carro pessoal, da família, dos vizinhos, de conhecidos, táxi...

6 Mais raramente, alguns também chegam de carro de polícia: trata-se geralmente de presos e, às vezes, de pessoas que a polícia recolheu na rua.

7 Exceto se foi encaminhada por um médico particular ou de um posto de saúde, o que é o caso de poucas. 
Ver o mapa do pronto-socorro em anexo.

9 Os motoristas de ambulância agem da mesma maneira quando levam ao prontosocorro um paciente grave, segundo sua avaliação.

10 Se tiver um médico atuando na triagem, o que não é sempre o caso, mesmo durante o dia.

11 Quando as equipes móveis não levam para o pronto-socorro um paciente que foram buscar é porque este fugiu antes de sua chegada ou se recusa a ir e atesta, por escrito, sua recusa (ou alguém de sua família, se ele é julgado incapaz de se pronunciar ou de decidir por ele mesmo).

12 Ver o mapa do pronto-socorro em anexo.

13 Isso, quando enfermeiras se deslocam para ir buscar na entrada pacientes que chegam de ambulância. Porque mesmo no caso dos que precisam de ajuda, como, por exemplo, de uma cadeira de rodas, é comum o próprio motorista, ajudado pelo segurança, cuidar deles, e acabar levando-os para dentro do pronto-socorro porque ninguém da enfermagem se apresenta.

14 Exemplos dessas conversas serão dados em um capítulo posterior.

15 Voltaremos a este ponto posteriormente.

16 Geralmente os que os bombeiros chamam de "caso psiquiátrico", "caso social" e "caso clínico", exceção feita ao enfarte.

17 Trata-se de um serviço social da prefeitura que funciona só de dia e possui uma ambulância que serve para o transporte das pessoas (inter-hospitalar, para fazer exames, levar os pacientes para casa etc).

18 Com exceção, claro, dos pedidos incompletos, no que diz respeito às indicações de localização (rua, número) e dos inúmeros trotes e enganos recebidos pela Central. 